\title{
Pattern of Dysglycaemia and Family Risk Factors for Diabetes Mellitus among Patients Attending General Outpatient Clinic of Federal Teaching Hospital Ido-Ekiti, Ekiti State, Nigeria
}

\author{
Gbadebo Oladimeji Ajani, Olusegun E. Gabriel-Alayode, Segun Alex Atolani, \\ Michael Osisiogu Soje, Michael Adeyemi Olamoyegun, Temitope Morenikeji Olarewaju, \\ and Oluwaserimi Adewumi Ajetunmobi
}

\section{ABSTRACT}

Diabetes mellitus is a non-communicable disease that currently affects over 366 million people worldwide and its prevalence is likely to double by 2030 . Therefore, the need to screen for diabetes mellitus has become an impetus. The objective of the study was to determine the prevalence of dysglycaemia and significance of familiar risk factors for diabetes mellitus among the study population.

One hundred and thirty-two and 48 consecutive non-previously diagnosed DM and previously diagnosed DM patients respectively were recruited from the same clinic. An interviewer administered questionnaire was applied and blood samples were taken for blood glucose. The prevalence of dysglycaemia was $36.2 \%$ and only $\mathbf{4 0 . 6 \%}$ of the diabetic patients who did fasting blood glucose had glycaemic control. Family history of Diabetes mellitus in the first generation was significantly associated with chance of developing diabetic mellitus in the study population.

In conclusion, it is important physicians begin to be very proactive in the screening for blood glucose in order to detect them early and forestall complications that are associated with late diagnosis of diabetes mellitus.

Keywords: Diabetes Mellitus, Dysglycaemia, Family history, Screening.

Published Online: December 21, 2020

ISSN: $2593-8339$

DOI: $10.24018 /$ ejmed.2020.2.6.590

\section{Gbadebo Oladimeji Ajani}

Endocrinology unit, Department of Medicine, Federal Teaching Hospital IdoEkiti, College of medicine, Afe Babalola University, Ado-Ekiti, Nigeria. (e-mail: gbadebo11@yahoo.com) Olusegun E. Gabriel-Alayode* College of medicine, Afe Babalola University, Ado-Ekiti, Department of Family Medicine, Federal Teaching Hospital, Ido-Ekiti, Nigeria.

(e-mail: layodeg@gmail.com) Segun Alex Atolani

Endocrinology unit, Department of Medicine, Federal Teaching Hospital, Ido-Ekiti, Nigeria.

(e-mail: toluwalaseatolani@ ${ }^{@ m a i l . c o m) ~}$ Michael Osisiogu Soje

College of medicine, Afe Babalola University, Ado-Ekiti, Renal Unit, department of Medicine, Federal Teaching Hopsital, Ido-Ekiti, Nigeria. (e-mail: mosoje@yahoo.com) Michael Adeyemi Olamoyegun Endocrinology unit, Department of Medicine, Ladoke Akintola University of Technology/LAUTECH Teaching Hospital Ogbomoso, Nigeria.

(e-mail: maolamoyegun ${ }^{\circledR}$ lautech.edu.ng) Temitope Morenikeji Olarewaju Department of Family Medicine, Federal Teaching Hospital, Ido-Ekiti, Nigeria. (e-mail: omt2k15@gmail.com) Oluwaserimi Adewumi Ajetunmobi Department of Family Medicine, Federal Teaching Hospital, Ido-Ekiti, Nigeria. (e-mail: wumiajet@ gmail.com)

*Corresponding Author

\section{INTRODUCTION}

Diabetes mellitus (DM) is a metabolic disorder that is characterized by glucose level over a prolonged period [1]. There are three main types of DM: Type 1 (arise from failure of pancreas to produce insulin), Type 2 (insulin resistance by body cells) and gestational diabetes (occurring for the first time in pregnancy) [2]. In 2017, an estimated of 425 million people had diabetes worldwide [3], with type 2 diabetes making up about $90 \%$ of the cases [4]. This represents $8.8 \%$ of the adult population [3], with equal rates in both women and men [5]. Studies have suggested that 
rates will continue to rise [3]. In Africa, Nigeria is the fourth country with the highest burden of diabetes with an estimated figure of over 1.7 million people living with the disease, but various reports indicate different prevalence rates [1]. Diabetes mellitus doubles a person's risk of early death due to the numerous complications (microvascular and macrovascular) it causes [2]. In 2017 alone, diabetes mellitus resulted in death of approximately 3.2 to 5.0 million people worldwide [3]. Despite the alarming increase in the rate of adult diagnosed with DM, many people are not taking to preventive measures. This prevention involves maintaining a healthy diet, regular physical exercise, a normal body weight, avoiding use of tobacco and regular screening for DM so as to be detected at the pre-diabetic stage during which DM can be curbed or delayed [2].

It is therefore imperative to verify the rate of dysglycaemia (pre-diabetic and diabetic glucose values) and possible risk factors for diabetes mellitus to facilitate appropriate health education and disease prevention measures. This will in turn help to curtail the morbidity and mortality which arise from complications of diabetes mellitus.

\section{Method OF THE STUDY}

The study was carried out to determine the pattern of dysglycaemia and specific risk factors for DM among patients attending the General Outpatient (GOP) Clinic of Federal Teaching Hospital Ido-Ekiti (FETHI). This study emanated from the free blood glucose screening to commemorate the 2019 diabetic week at FETHI. One hundred and thirty-two consecutive and consenting participants that were not known to have diabetes mellitus were recruited in the GOP clinic of the Hospital and 48 consecutive and consenting participants who have been diagnosed and on treatment for diabetes mellitus were also recruited from the same clinic. This is for the purpose of comparison of family risk factors for diabetes mellitus between the diabetic and non-diabetic patients. Adult patients aged 15 to 80 years and patients on only antidiabetic medications were recruited into the study while critically ill patients were excluded. Some of the participants had fasting blood glucose (FBG) done while some had random blood glucose (RBG) done due to the fact that there was no prior knowledge of having to do the test. All the participants had their blood sugar checked using validated Accu-Chek Active Glucometer, the blood sugar was done between 7.30 am and 9.0 am daily for one week and the results were recorded in the questionnaire. The Accu-Chek Active system uses a capillary blood sample which is set to plasma serum standard, showing result in plasma glucose values. Written consent was obtained from the participants and ethical clearance was obtained from the Hospital Research and Ethics Committee.

\section{DATA ANALYSIS}

Data collected were analyzed using Statistical Package for Social Science version 21.0. The data were presented in tabular forms and charts as appropriate. Statistics such as mean, mode, median and standard deviation were determined. Association between dependent and independent variables were compared using Pearson's chi square and Fischer exact test as appropriate. The level of statistical significance was taken as P-value of equal or less than 0.05 .

\section{RESULT}

The mean age of the respondents was $48.39 \pm 15.78$ years, the modal age group was 30-39 years and male to female ratio of the respondents was 1:2.2. Majority of the patients had tertiary education $(45.6 \%)$; class 3 occupational status was the commonest $(31.1 \%)$ while Yoruba was the preponderant ethnic group $(84.4 \%)$.

\begin{tabular}{|c|c|c|}
\hline $\begin{array}{l}\text { Sociodemographic } \\
\text { factors }\end{array}$ & No (180) & $\%$ \\
\hline \multicolumn{3}{|l|}{ Age group } \\
\hline $10-19$ & 05 & 2.8 \\
\hline $20-29$ & 11 & 6.1 \\
\hline $30-39$ & 45 & 25.0 \\
\hline $40-49$ & 39 & 21.7 \\
\hline $50-59$ & 37 & 20.5 \\
\hline $60-69$ & 21 & 11.7 \\
\hline $70-79$ & 15 & 8.3 \\
\hline $80-89$ & 07 & 3.9 \\
\hline \multicolumn{3}{|l|}{ Gender } \\
\hline Male & 56 & 31.1 \\
\hline Female & 124 & 68.9 \\
\hline \multicolumn{3}{|l|}{ Education } \\
\hline Primary & 13 & 7.2 \\
\hline Secondary & 70 & 38.9 \\
\hline Tertiary & 82 & 45.6 \\
\hline None & 15 & 8.3 \\
\hline \multicolumn{3}{|l|}{ Occupation } \\
\hline Grade 1 & 2 & 1.1 \\
\hline Grade 2 & 50 & 27.8 \\
\hline Grade 3 & 56 & 31.0 \\
\hline Grade 4 & 30 & 16.7 \\
\hline Grade 5 & 12 & 6.7 \\
\hline Grade 6 & 30 & 16.7 \\
\hline \multicolumn{3}{|l|}{ Ethnicity } \\
\hline Yoruba & 152 & 84.4 \\
\hline Hausa & 09 & 5.1 \\
\hline Ibo & 08 & 4.4 \\
\hline Others & 11 & 6.1 \\
\hline
\end{tabular}

Occupation: grade 1- professional/ contractors/ Business tycoon.

Grade 2 - senior civil servants/ secondary school teacher.

Grade 3 - intermediate civil servants/ primary school teachers/ Artisans.

Grade 4- messengers, small scale traders.

Grade 5 - unemployed.

Grade 6 - retirees.

Table 2 shows that $27.5 \%$ of the participants who did fasting blood glucose had dysglycaemia, while $8.7 \%$ of those who did random blood glucose had dysglycaemia. Overall, 36.2\% had dysglycaemia.

Among the known diabetic patients on antidiabetic medication, $40.6 \%$ had glycaemic control with fasting blood glucose, and $75 \%$ with random blood sugar had glyacemic control based on a single test done using glucometer.

Table 3 below shows that increasing age is significantly associated with development of diabetes mellitus, and statistically significant number of patients with diabetes mellitus had history of DM in the first generation. There is no statistically significant association between history of $\mathrm{DM}$ in the second degree relative and diabetes mellitus in 
the participants, though there is an increase in rate of development diabetes mellitus with positive history in the second generation.

\begin{tabular}{|c|c|c|}
\hline Blood sugar pattern (in mmol/L) & Frequency & $\%$ \\
\hline \multicolumn{3}{|l|}{ FBG in non-diabetics (40) } \\
\hline Normal $(\leq 5.5)$ & 29 & 72.5 \\
\hline Pre-diabetic (5.6-6.9) & 9 & 22.5 \\
\hline Diabetic $(\geq 7.0)$ & 2 & 5.0 \\
\hline \multicolumn{3}{|l|}{ RBG in non-diabetics (92) } \\
\hline Normal $(<7.8)$ & 84 & 91.3 \\
\hline Pre-diabetic (7.8 -11) & 7 & 7.6 \\
\hline Diabetic $(\geq 11.1)$ & 1 & 1.1 \\
\hline \multicolumn{3}{|l|}{ FBG in known diabetics (32) } \\
\hline$<4.4$ (hypoglycaemia) & 0 & 0 \\
\hline $4.4-7.2$ (control) & 13 & 40.6 \\
\hline$>7.2$ (uncontrol) & 19 & 59.4 \\
\hline \multicolumn{3}{|l|}{ RBG in known diabetics (16) } \\
\hline$<10$ (control) & 12 & 75.0 \\
\hline$\geq 10$ (uncontrol) & 4 & 25.0 \\
\hline
\end{tabular}

TABLE 3: The RELATIONSHIP BETWEEN DiABETIC MELLitus AND FAMILY

\begin{tabular}{|c|c|c|c|c|}
\hline \multicolumn{3}{|c|}{ HISTORY } & \multirow[b]{2}{*}{$\chi^{2}$} & \multirow[b]{2}{*}{$\begin{array}{c}\mathrm{P}- \\
\text { value }\end{array}$} \\
\hline & $\begin{array}{c}\text { Yes } 48 \\
(\%)\end{array}$ & No $132(\%)$ & & \\
\hline \multicolumn{5}{|l|}{ Age group } \\
\hline $10-19$ & $2(40.0)$ & $3(60.0)$ & \multirow{8}{*}{25.87} & \multirow{8}{*}{0.001} \\
\hline $20-29$ & $0(0.0)$ & $11(100.0)$ & & \\
\hline $30-39$ & $6(13.3)$ & $39(86.6)$ & & \\
\hline $40-49$ & $7(17.9)$ & $32(82.1)$ & & \\
\hline $50-59$ & $11(29.7)$ & $26(70.3)$ & & \\
\hline $60-69$ & $13(61.9)$ & $8(38.1)$ & & \\
\hline $70-79$ & $6(40.0)$ & $9(60.0)$ & & \\
\hline $80-89$ & $3(42.9)$ & $4(57.1)$ & & \\
\hline \multicolumn{5}{|c|}{$\begin{array}{l}\text { Family History of DM in } \\
\text { first degree relative }\end{array}$} \\
\hline$(\mathrm{n}=180)$ & $18(69.2)$ & $8(30.8)$ & \multirow[t]{3}{*}{28.7} & \multirow[t]{3}{*}{0.001} \\
\hline Yes & $30(19.9)$ & $121(80.1)$ & & \\
\hline $\begin{array}{l}\text { No } \\
\text { I do not know }\end{array}$ & $0(0.0)$ & $3(100.0)$ & & \\
\hline \multicolumn{5}{|c|}{$\begin{array}{l}\text { Fam. History of } \mathrm{Dm} \text { in } \\
2^{\text {nd }} \text { degree relatives }\end{array}$} \\
\hline$(\mathrm{n}=180)$ & & & \multirow[t]{4}{*}{5.497} & \multirow[t]{4}{*}{0.064} \\
\hline Yes & $5(62.5)$ & $3(37.5)$ & & \\
\hline No & $40(25.0)$ & $120(75.0)$ & & \\
\hline I don't know & $3(25.0)$ & $9(75.0)$ & & \\
\hline
\end{tabular}

Table 4 below showed that there is no statistically significant association between age, gender, education, occupation, ethnicity and dysglycaemia among the respondents. Nevertheless, from age 30 years there is increase in the rate of dysglycaemia to age 69 years (see Fig. 1 below). Dysglycamia is found among female than male and $50 \%$ of people with no education has dysglycaemia as compared with $18.8 \%$ and $28.6 \%$ of people with secondary and tertiary education respectively. Conversely dysglycaemia is found more among those who did not have history of DM in first degree or secondary relations (11\% in both)

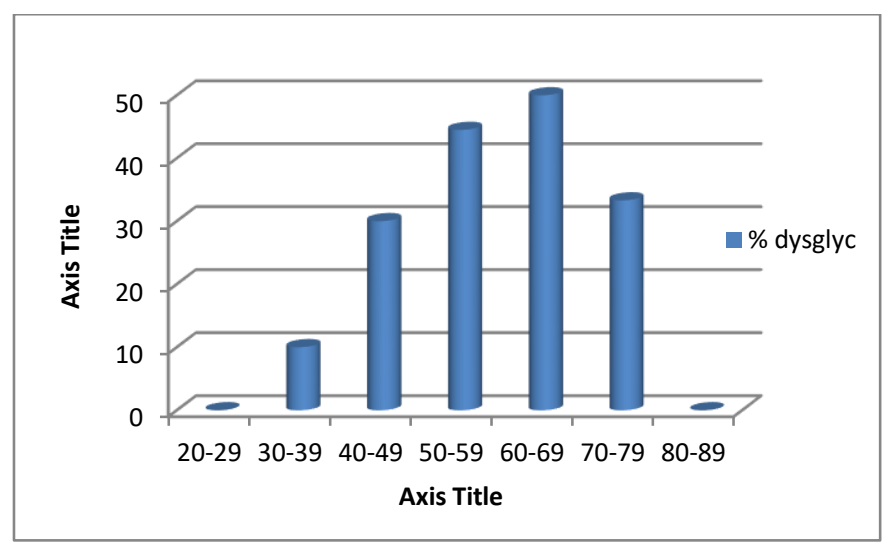

Fig. 1. Pattern of dysglycaemia across age groups (using FBG).

TABLE 4: RELATIONSHIP BETWEEN SOCIODEMOGRAPHIC FACTORS AND DYSGLYCAEMIA USING FBG

\begin{tabular}{|c|c|c|c|c|}
\hline \multicolumn{5}{|c|}{ DYSGLYCAEMIA USING FBG } \\
\hline & \multicolumn{2}{|c|}{ FBG in non-diabetic patients } & \multirow{2}{*}{ Chi sq. } & \multirow{2}{*}{ p-value } \\
\hline & Normal & dysglycaemia & & \\
\hline \multicolumn{5}{|l|}{ Age group } \\
\hline $20-29$ & $2(100)$ & $0(0)$ & \multirow{7}{*}{9.202} & \multirow{7}{*}{0.686} \\
\hline $30-39$ & $9(90)$ & $1(10)$ & & \\
\hline $40-49$ & $7(70)$ & $3(30)$ & & \\
\hline $50-59$ & $5(55.5)$ & $4(44.5)$ & & \\
\hline $60-69$ & $2(50)$ & $2(50)$ & & \\
\hline $70-79$ & $2(66.7)$ & $1(33.3)$ & & \\
\hline $80-89$ & $2(100)$ & $0(0)$ & & \\
\hline \multicolumn{5}{|l|}{ Sex } \\
\hline Male & $9(100)$ & $0(0)$ & \multirow[t]{2}{*}{4.405} & \multirow[t]{2}{*}{0.111} \\
\hline Female & $20(64.5)$ & $11(35.5)$ & & \\
\hline \multicolumn{5}{|c|}{ Level of education } \\
\hline Primary & $3(75)$ & $1(25)$ & \multirow{4}{*}{12.358} & \multirow{4}{*}{0.054} \\
\hline Secondary & $13(81.2)$ & $3(18.8)$ & & \\
\hline Tertiary & $10(71.4)$ & $4(28.6)$ & & \\
\hline No education & $3(50)$ & $3(50)$ & & \\
\hline \multicolumn{5}{|l|}{ Occupation } \\
\hline Grade 1 & $0(0)$ & $0(0)$ & \multirow{6}{*}{12.598} & \multirow{6}{*}{0.126} \\
\hline Grade2 & $12(100)$ & $0(0)$ & & \\
\hline Grade3 & $10(66.7)$ & $5(33.3)$ & & \\
\hline Grade4 & $2(28.6)$ & $5(71.4)$ & & \\
\hline Grade5 & $2(100)$ & $0(0)$ & & \\
\hline Retiree & $3(75)$ & $1(25)$ & & \\
\hline \multicolumn{5}{|l|}{ Ethnicity } \\
\hline Yoruba & $26(70.3)$ & 11(29.7) & \multirow{4}{*}{1.230} & \multirow{4}{*}{0.975} \\
\hline Ibo & $1(100)$ & $0(0)$ & & \\
\hline Hausa & $1(100)$ & $0(0)$ & & \\
\hline Other & $1(100)$ & $0(0)$ & & \\
\hline \multicolumn{5}{|c|}{$\begin{array}{l}\text { Fam hist of DM in } \\
\text { 1st generation }\end{array}$} \\
\hline Yes & $2(100)$ & $0(0)$ & \multirow[t]{3}{*}{0.799} & \multirow[t]{3}{*}{0.671} \\
\hline No & $27(71.1)$ & $11(28.9)$ & & \\
\hline I don't know & 0 & 0 & & \\
\hline \multicolumn{5}{|c|}{$\begin{array}{l}\text { Fam hist of DM 2nd } \\
\text { generation }\end{array}$} \\
\hline Yes & $0(0)$ & $0(0)$ & \multirow[t]{3}{*}{0.389} & \multirow[t]{3}{*}{0.823} \\
\hline No & $28(71.8)$ & $11(28.2)$ & & \\
\hline I don't know & $1(100$ & $0(0)$ & & \\
\hline
\end{tabular}

There is increase in the rate of dysglycaemia with increasing age until age 70 years when there is a decline. Table 5 below shows that there is a statistically significant association between age and dysglycaemia with participants who had random blood glucose assessment. However no statistically significant relationship between gender, occupation, education, ethnicity and dysglycaemia among participants who had Random Blood Glucose assessment done. Against the expected, dysglycaemia was commoner among participants with no history of DM in the first degree relative but higher among participants with positive family history of DM in the secondary degree relatives. 
TABLE 5: RELATIONSHIP BETWEEN SOCIODEMOGRAPHIC FACTORS AND DYSGLYCAEMIA USING RBG

\begin{tabular}{|c|c|c|c|c|}
\hline & \multicolumn{2}{|c|}{$\begin{array}{l}\text { RBG in non-diabetic } \\
\text { patient (92) }\end{array}$} & \multirow{2}{*}{ Chi sq } & \multirow{2}{*}{ P-value } \\
\hline & $\begin{array}{c}\text { Normal } \\
(\%)\end{array}$ & dysglycaemia & & \\
\hline \multicolumn{5}{|l|}{ Age group (92) } \\
\hline $10-19$ & $3(100)$ & $0(0)$ & \multirow{8}{*}{54.803} & \multirow{8}{*}{0.001} \\
\hline $20-29$ & $9(100)$ & $0(0)$ & & \\
\hline $30-39$ & $28(96.6)$ & $1(3.4)$ & & \\
\hline $40-49$ & $20(90.9)$ & $2(9.1)$ & & \\
\hline $50-59$ & $15(88.2)$ & $2(11.8)$ & & \\
\hline $60-69$ & $4(100)$ & $0(0)$ & & \\
\hline $70-79$ & $5(83.3)$ & $1(16.7)$ & & \\
\hline $80-89$ & $0(0)$ & $2(100)$ & & \\
\hline \multicolumn{5}{|l|}{$\operatorname{Sex}(92)$} \\
\hline Male & $31(86.1)$ & $5(13.9)$ & \multirow[t]{2}{*}{2.684} & \multirow[t]{2}{*}{0.261} \\
\hline Female & 53(94.6) & $3(5.4)$ & & \\
\hline \multicolumn{5}{|c|}{$\begin{array}{l}\text { Level of education } \\
\text { (92) }\end{array}$} \\
\hline Primary & $4(100)$ & 0 & \multirow{4}{*}{8.119} & \multirow{4}{*}{0.230} \\
\hline Secondary & $29(90.6)$ & $3(9.4)$ & & \\
\hline Tertiary & $47(94.0)$ & $3(6.0)$ & & \\
\hline No education & $4(66.7)$ & $2(33.3)$ & & \\
\hline \multicolumn{5}{|l|}{ Occupation (92) } \\
\hline Grade 1 & $2(100)$ & $0(0)$ & \multirow{6}{*}{8.075} & \multirow{6}{*}{0.622} \\
\hline Grade2 & $29(93.5)$ & $2(6.5)$ & & \\
\hline Grade3 & $22(91.7)$ & $2(8.3)$ & & \\
\hline Grade4 & $15(93.8)$ & $1(6.2)$ & & \\
\hline Grade5 & $7(87.5)$ & $1(12.5)$ & & \\
\hline Retiree & $9(81.8)$ & $2(18.2)$ & & \\
\hline \multicolumn{5}{|l|}{ Ethnicity (92) } \\
\hline Yoruba & $66(90.4)$ & $7(9.6)$ & \multirow{4}{*}{2.088} & \multirow{4}{*}{0.911} \\
\hline Ibo & $6(100)$ & $0(0)$ & & \\
\hline Hausa & $5(83.3)$ & 1(16.7) & & \\
\hline Other & $7(100)$ & $0(0)$ & & \\
\hline \multicolumn{5}{|c|}{$\begin{array}{l}\text { Fam hist of DM in } \\
1^{\text {st }} \text { Gen. }\end{array}$} \\
\hline Yes & $6(100)$ & $0(0)$ & \multirow[t]{3}{*}{0.950} & \multirow[t]{3}{*}{0.917} \\
\hline No & $75(90.4)$ & $8(9.6)$ & & \\
\hline I don't know & $3(100)$ & $0(0)$ & & \\
\hline \multicolumn{5}{|c|}{$\begin{array}{l}\text { Fam hist of Dm in } \\
2^{\text {nd }} \text { Gen }\end{array}$} \\
\hline Yes & $2(67.7)$ & 1(33.3) & \multirow[t]{3}{*}{3.624} & \multirow[t]{3}{*}{0.459} \\
\hline No & 74(91.4) & $7(8.6)$ & & \\
\hline I don't know & $8(100)$ & $0(0)$ & & \\
\hline
\end{tabular}

\section{DISCUSSION}

The study aimed at determining the pattern of dysglycaemia among patients attending the general outpatient clinic of Federal Teaching Hospital Ido-Ekiti. One hundred and eighty participants were screened in the clinic using Accu-Chek Active glucometer, 132 were not known diabetics and 48 were previously known diabetic patients. The mean age of the respondents was $48.39 \pm 15.78$, the modal age group was 30-39 and male to female ratio of the respondents was 1:2.2. The ratio of female doubles the male in this study; this is in consonant with some other studies [6], [7]. In many studies women were found to visit health facilities more often than men [6], [7]. Several studies reported higher levels of non-attendance among male patients than females [6], [7]. Sharp and Hamilton in their study provided an informal review of the evidence on nonattendance and reported that being male was one of the main associations with hospital non-attendance [6]. Moore et al investigated over 4000 appointments at a family practice centre in the USA and found that females tended to be less likely to miss appointments than males [7].

From age 30 years there is an increase in the rate of dysglycaemia to age 69 years (Fig. 1). Dysglycamia was found more among female than male and $50 \%$ of people with no education had dysglycaemia compared to $18.8 \%$ and $28.6 \%$ of people with secondary and tertiary education respectively [8]. A meta-analysis found that impaired glucose tolerance was found to be more common among women than among men and aging was also found to be significantly associated with impaired glucose tolerance [4]. In general, women have a smaller mass of muscle than men and therefore less muscle available for the uptake of the fixed glucose load $(75 \mathrm{~g})$ used in the oral glucose-tolerance test. Women also have relatively high levels of estrogen and progesterone, both of which can reduce whole-body insulin sensitivity [4], [8].

The prevalence of dysglycaemia in this study was $36.2 \%$ which means that about 4 out of 10 participants had dysglycaemia among patients visiting our hospital for other reasons. Sixteen of them $(30.1 \%)$ were at pre-diabetic stage and $3(6.1 \%)$ met the criterion for diagnosis of diabetic mellitus in this study. A systematic review and metal analysis study showed that prevalence of diabetes mellitus in Nigeria ranges from $2 \%$ to $12 \%$ depends on the geopolitical zone, $5.5 \%$ was reported in south west and $9.8 \%$ in the south-south [4]. This is comparable to $6.1 \%$ found in this study. Likewise, a study done in Ethiopia, the prevalence of DM was found to be $6.5 \%$ (26 out of 402) [9]. Of which, the proportion of previously undiagnosed diabetes mellitus was $88.5 \%$. The prevalence of pre-diabetes was also found to be $15.9 \%$ in the same Ethiopia study, [9] which is almost half of pre-diabetes mellitus in our study. This is a community based cross-sectional study unlike in our study where hospital based cross-sectional study was conducted and this could account for the differences in the findings.

According to the International Diabetes Federation (IDF), 425 million persons are currently living with DM worldwide, with nearly $50 \%$ of this undiagnosed [3]. The developing economies of Africa and Asia were said to contribute a significant fraction of this figure. There is also a rising burden from the complications of DM alongside the ever-increasing prevalence of the disease [3]. It is therefore important to be proactive in our consultations as physicians in Nigeria, not only to treat the complaints presented by the patients but also to screen for other health conditions like diabetes mellitus. It was also found in this study that increasing age and family history of diabetes mellitus were significantly associated with development of diabetes mellitus. Participants who were previously diagnosed to be diabetic were found to have family history of diabetes mellitus especially in the first degree relatives. Similarly, a metal analysis reported that risk factors for the pooled prevalence of DM were a family history of DM and older age among others like urban dwelling, unhealthy dietary habits; cigarette smoking, physical inactivity, and obesity [4], [8]. However, in our study, gender, occupation, educational attainment, and ethnicity were not significantly associated with dysglycaemia as found in other studies [9], [10].

Among the diabetic patients who had their fasting blood sugar done, only $40.6 \%$ had good blood sugar control while in those who had random blood sugar done $75 \%$ had good control as at the time of the screening. The percentage of 
patients with controlled fasting blood sugar in this studgy is unacceptably low though this is higher than the prevalence of controlled blood sugar (13.6\%) reported in a study done in Ghana by Flagbe J et al. [11]. A multicenter study across seven tertiary health centers in Nigeria also reported that $32.4 \%$ and $20.4 \%$ patients achieved the ADA and IDF glycemic targets, respectively (though HbAIC was used in this study) [12]. The reasons for these variations in glycaemic control across countires and zones could be multi-factorial e.g., method of glycaemic analysis, poor adherence to medication, poor patient-doctor relationship, none keeping to medical appointment given etc.

In conclusion, the proportion of dysgylcamia in this study is unacceptably high, hence Physicians should be more proactive to screen patients for blood sugar so as to detect many at pre-diabetes stage. The proportion that will develop diabetic mellitus could be reduced through appropriate health education on lifestyle modification.

\section{REFERENCES}

[1] Otovwe A, Oyewole OE, Igumbor EO, Nwose EU. Diabetes care in delta state of Nigeria: An expository review. Diabetes Updates. 2018 Aug;4(1):1-8.

[2] Karaoui LR, Deeb ME, Nasser L, Hallit S. Knowledge and practice of patients with diabetes mellitus in Lebanon: a cross-sectional study. BMC public health. 2018 Dec 1;18(1):525.

[3] Ogbera AO, Ekpebegh C. Diabetes mellitus in Nigeria: The past, present and future. World journal of diabetes. 2014 Dec 15;5(6):905.

[4] Uloko AE, Musa BM, Ramalan MA, Gezawa ID, Puepet FH, Uloko AT, Borodo MM, Sada KB. Prevalence and risk factors for diabetes mellitus in Nigeria: a systematic review and meta-analysis. Diabetes Therapy. 2018 Jun 1;9(3):1307-16.

[5] Mandal A. Study of prevalence of type 2 diabetes mellitus and hypertension in overweight and obese people. Journal of family medicine and primary care. $2014 \mathrm{Jan} ; 3(1): 25$.

[6] Sharp DJ, Hamilton W. Non-attendance at general practices and

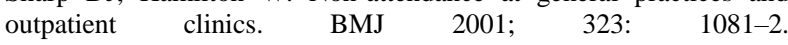
10.1136/bmj.323.7321.1081. [PubMed] [CrossRef] [Reference list].

[7] Moore CG, Wilson-Witherspoon P, Probst JC. Time and money: effects of no-shows at a family practice residency clinic. Fam Med 2001; 33: 522-7. [PubMed] [Reference list].

[8] Hilawe EH, Yatsuya H, Kawaguchi L, Aoyama A. Differences by sex in the prevalence of diabetes mellitus, impaired fasting glycaemia and impaired glucose tolerance in sub-Saharan Africa: a systematic review and meta-analysis. Bulletin of the World Health Organization. 2013; 91: 671-82D.

[9] Aynalem SB, Zeleke AJ. Prevalence of diabetes mellitus and its risk factors among individuals aged 15 years and above in Mizan-Aman town, Southwest Ethiopia, 2016: a cross sectional study. International journal of endocrinology. 2018 Jan 1; 2018.

[10] Ekpenyong CE, Akpan UP, Ibu JO, Nyebuk DE. Gender and age specific prevalence and associated risk factors of type 2 diabetes mellitus in Uyo Metropolis, South Eastern Nigeria. Diabetologia Croatica 2012; 41:17-23.

[11] Fiagbe J, Bosoka S, Opong J, Takramah W, Axame WK, Owusu R, Parbey PA, Adjuik M, Tarkang E, Kweku M. Prevalence of controlled and uncontrolled diabetes mellitus and associated factors of controlled diabetes among diabetic adults in the Hohoe municipality of Ghana. Diabetes Management. 2017;7(5):343-54.

[12] Chinenye S, Uloko AE, Ogbera AO, Ofoegbu EN, Fasanmade OA, Fasanmade AA, Ogbu OO. Profile of Nigerians with diabetes mellitus-Diabcare Nigeria study group (2008): Results of a multicenter study. Indian journal of endocrinology and metabolism. 2012 Jul;16(4):558. 